\title{
Is sciatic nerve block advantageous when combined with femoral nerve block for postoperative analgesia following total knee arthroplasty? a meta-analysis
}

\section{Le bloc du nerf sciatique est-il bénéfique lorsqu'il est combiné à un bloc du nerf fémoral pour l'analgésie postopératoire après une arthroplastie totale du genou? Une méta-analyse}

\author{
Faraj W. Abdallah, MD • Caveh Madjdpour, MD $\cdot$ Richard Brull, MD \\ Received: 15 April 2015/Revised: 18 November 2015/Accepted: 8 February 2016/Published online: 19 February 2016 \\ (C) Canadian Anesthesiologists' Society 2016
}

\begin{abstract}
Background Total knee arthroplasty (TKA) is associated with moderate-to-severe postoperative pain despite the use of femoral nerve block (FNB). The analgesic benefits of adding sciatic nerve block (SNB) to FNB following TKA are unclear. The aim of this meta-analysis was to quantify the analgesic effects of adding SNB to FNB following TKA. Methods We searched the US National Library of Medicine (MEDLINE), Excerpta Medica (Embase), and Cochrane Central Controlled Trials Register databases in March 2015 for randomized and quasi-randomized controlled trials (RCTs) that evaluated the analgesic advantages of adding SNB to FNB compared to FNB alone after TKA. The designated primary outcome was intravenous morphine consumption during the 24-hr postoperative interval. The severity of pain was evaluated at rest and with movement two, four, eight, 12, 24, 36, and $48 \mathrm{hr}$ postoperatively. Morphine consumption during the postoperative 24-48 hr interval, time to first analgesic request, opioid-related side effects, block-related complications, patient satisfaction, functional recovery, and time to hospital discharge were also evaluated. Trials were stratified based on whether a single-shot SNB (SSNB)
\end{abstract}

This article is accompanied by an editorial. Please see Can J Anesth 2016; 63: this issue.

F. W. Abdallah, MD ( $\square)$

Department of Anesthesia, St. Michael's Hospital, 30 Bond

Street, Toronto, ON M5B 1W8, Canada

e-mail: AbdallahF@smh.ca

C. Madjdpour, MD $\cdot$ R. Brull, MD

Department of Anesthesia, Toronto Western Hospital, University

Health Network, University of Toronto, Toronto, ON, Canada or continuous SNB (CSNB) was used. Data were combined using random effects modelling.

Results Eight RCTs, including 379 patients, were analyzed. Five trials examined SSNB, and three assessed CSNB. Together, SSNB and CSNB reduced the 0-24 hr weighted mean difference [95\% confidence interval] of morphine consumption by $10.6[-20.9$ to -0.3$] \mathrm{mg}(P=$ $\left.0.042 ; I^{2}=97 \%\right)$ and $20.5[-28.6$ to -12.4$] \mathrm{mg}(P<$ $\left.0.001, I^{2}=86 \%\right)$, respectively. SSNB reduced pain at rest and during movement up to $8 \mathrm{hr}$ postoperatively $(P=0.023$ and $P<0.001$, respectively), whereas $C S N B$ reduced pain at rest up to $36 \mathrm{hr}(P=0.004)$ and pain with movement up to $48 \mathrm{hr}(P=0.031)$. CSNB also decreased the odds of postoperative nausea and vomiting by $91 \%(P=0.011)$.

Conclusion The available evidence supporting the analgesic benefits of adding SNB to FNB following TKA is marked by significant heterogeneity. With this challenge in mind, our meta-analysis suggests that SNB can significantly reduce postoperative opioid consumption and diminish knee pain following TKA compared to no $S N B$ in the setting of FNB.

Résumé

Contexte L'arthroplastie totale du genou (ATG) est associée à une douleur postopératoire modérée à grave malgré le recours au bloc du nerf fémoral (BNF). Les avantages analgésiques de l'ajout d'un bloc du nerf sciatique (BNS) au FNB après une ATG sont mal connus. $L$ 'objectif de cette méta-analyse était de quantifier les effets analgésiques de l'ajout d'un BNS au BNF après une ATG. Méthode Nous avons lancé une recherche dans les bases de données de la Bibliothèque nationale de médecine américaine (MEDLINE), Excerpta Medica (Embase), et du Registre central des études contrôlées Cochrane en mars 
2015 pour en tirer les études randomisées et quasi-randomisées contrôlées (ERC) évaluant les avantages analgésiques de l'ajout d'un BNS au BNF par rapport à un BNF seul après une ATG. Le critère d'évaluation principal désigné était la consommation de morphine intraveineuse pendant un intervalle postopératoire de $24 \mathrm{~h}$. La gravité de la douleur a été évaluée au repos et en mouvement à deux, quatre, huit, 12, 24, 36 et 48 hostopératoires. La consommation de morphine pendant l'intervalle postopératoire de 24-48 h, le temps jusqu'à la première demande d'analgésique, les effets secondaires liés aux opiö̈des, les complications liées au bloc, la satisfaction des patients, la récupération fonctionnelle et le temps jusqu'au congé de l'hôpital ont également été évalués. Les études ont été stratifiées selon leur recours à une injection unique pour le BNS (BNS-U) ou à une perfusion continue (BNS-C). Les données ont été combinées à l'aide d'un modèle à effets aléatoires.

Résultats Huit ERC, incluant 379 patients, ont été analysées. Cinq études examinaient le BNS-U, et trois évaluaient le BNS-C. Ensemble, le BNS-U et le BNS-C ont réduit la différence moyenne pondérée pour la période 0 -24 h [intervalle de confiance $95 \%$ ] de consommation de morphine de 10,6 [-20,9 à -0,3] $\mathrm{mg}\left(P=0,042 ; I^{2}=\right.$ $97 \%)$ et de 20,5 [-28,6 à -12,4] mg $(P<0,001, I 2=86$ $\%)$, respectivement. Le BNS-U a réduit la douleur au repos et en mouvement jusqu'à 8 h après l'opération $(P=0,023$ et $P<0,001$, respectivement), alors que le $B N S-C$ a réduit la douleur au repos jusqu'à $36 h(P=0,004)$ et la douleur en mouvement jusqu'à $48 h(P=0,031)$. Le BNS-C a également réduit le risque de nausées et vomissements postopératoires de $91 \%(P=0,011)$.

Conclusion Les données probantes à disposition appuyant les avantages analgésiques de l'ajout d'un BNS au BNF après une ATG sont sujettes à une importante hétérogénéité. Tout en gardant cette difficulté à l'esprit, notre méta-analyse laisse à penser que le BNS pourrait réduire de façon significative la consommation postopératoire d'opiö̈des et diminuer la douleur au genou après une ATG par rapport à l'absence de BNS dans le cadre d'un BNF.

The number of total knee arthroplasties (TKAs) performed annually in the United States has doubled during the last decade. ${ }^{1}$ Although the potential for local infiltration analgesia $(\mathrm{LIA})^{2}$ and adductor canal block ${ }^{3}$ techniques await to be fully elucidated, ${ }^{4}$ in many centres femoral nerve block (FNB) remains a mainstay of multi-modal analgesic management following TKA. ${ }^{5-9}$ Despite a functioning FNB, however, TKA continues to be associated with moderate-to-severe postoperative pain in the majority of patients. ${ }^{10}$ To improve pain control, it has been suggested that proximal sciatic nerve block (SNB) performed between the parascacral and mid-thigh regions should be added to FNB in patients undergoing TKA. ${ }^{11-13}$ Unfortunately, the relevant evidence examining the role of SNB had been limited to observational studies and lowquality randomized controlled trials (RCTs), thus precluding a valid and reliable estimation of effect. ${ }^{14}$ Recently, however, nine RCTs have been separately published, with seemingly mixed results. ${ }^{15-23}$ In this updated meta-analysis, we aimed to quantify the analgesic effects of adding proximal single-shot or continuous SNB to single-shot or continuous FNB in the absence of LIA on analgesic consumption and pain scores during the first $48 \mathrm{hr}$ postoperatively in adult patients undergoing unilateral TKA.

\section{Methods}

The Preferred Reporting Items for Systematic Reviews and Meta-Analysis (PRISMA) guidelines ${ }^{24}$ were followed while preparing this systematic quantitative review. Randomized and quasi-randomized controlled trials examining the analgesic effects of adding SNB to FNB following TKA were retrieved and reviewed with an $a$ priori designed but unregistered systematic review protocol.

Literature search

Two authors (F.W.A., R.B.) separately searched the US National Library of Medicine database (MEDLINE), Excerpta Medica database (Embase), Medline In Process, Cochrane Central Controlled Trials Database Register, Cochrane Systematic Reviews Database, and other nonindexed databases of citations. The search was conducted for medical subject headings (MeSH), controlled terms, and text words relevant to the components of the study question of this review. They encompassed sciatic nerve block, knee arthroplasty or replacement, postoperative pain, and analgesia. The terms were used individually and in combinations (Appendix). We also hand-searched the bibliography sections of the manuscripts retrieved to identify any additional studies that met our eligibility criteria. Trials involving human adults (18 yr or older) published from January $1950^{25,26}$ to March 2015 were considered. We also sought and reviewed related abstracts of meetings of the following medical professional societies: American Society of Regional Anesthesia (2005-2014), American Society of Anesthesiologists 
Fig. 1 Flowchart summarizes the study selection process and depicts retrieved, included, and excluded randomized controlled trials

\section{Citations of potentially relevant articles identified through search strategies}

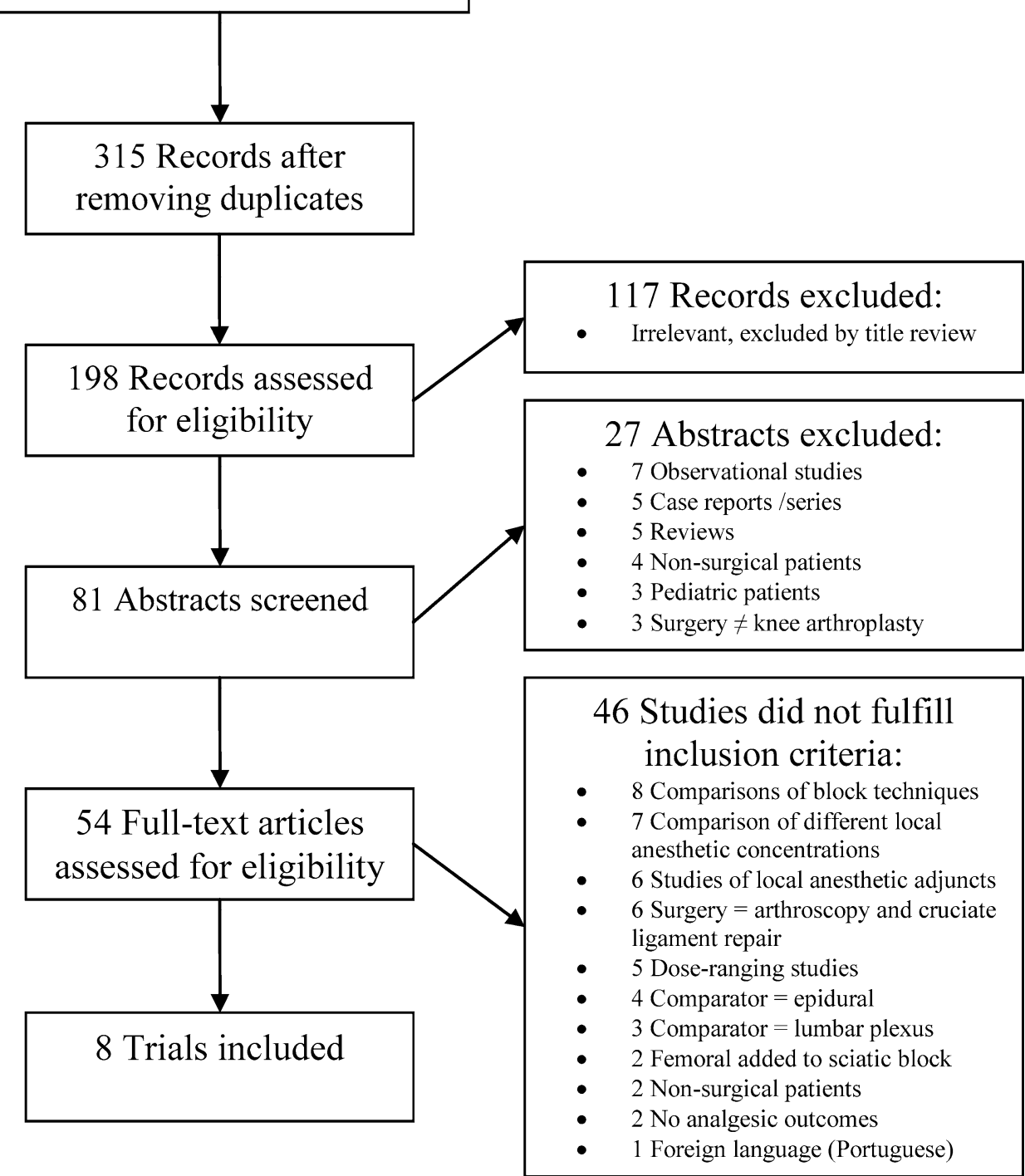

(2000-2014), and the European Society of Regional Anesthesia (2006-2014). In addition, the Internet-based registries of clinical trials including www.clinicaltrials.gov, www.ISRCTN.org, https://www.clinicaltrialsregister.eu, and http://www.anzctr.org.au were examined for ongoing relevant trials.

\section{Eligibility criteria}

We retrieved complete manuscripts and published abstracts of trials that evaluated the impact of single-shot or catheter-based infusion proximal SNB (i.e., parasacral, Labat, infragluteal, anterior, and mid-femoral approaches)
(SNB group) compared to placebo or systemic intravenous analgesia (Control group) on postoperative analgesic outcomes in patients undergoing unilateral TKA. Only RCTs in which single-shot or continuous FNB was administered to both groups were included. RCTs examining blocks performed for surgical anesthesia and/ or postoperative analgesia were also eligible. We excluded trials that (1) did not assess analgesic outcome measures (i.e., pain severity scores or postoperative analgesic consumption); (2) were performed only as distal (i.e., popliteal) SNB; (3) made it impossible to evaluate the analgesic impact of SNB separately from other coanalgesic interventions that were simultaneously 


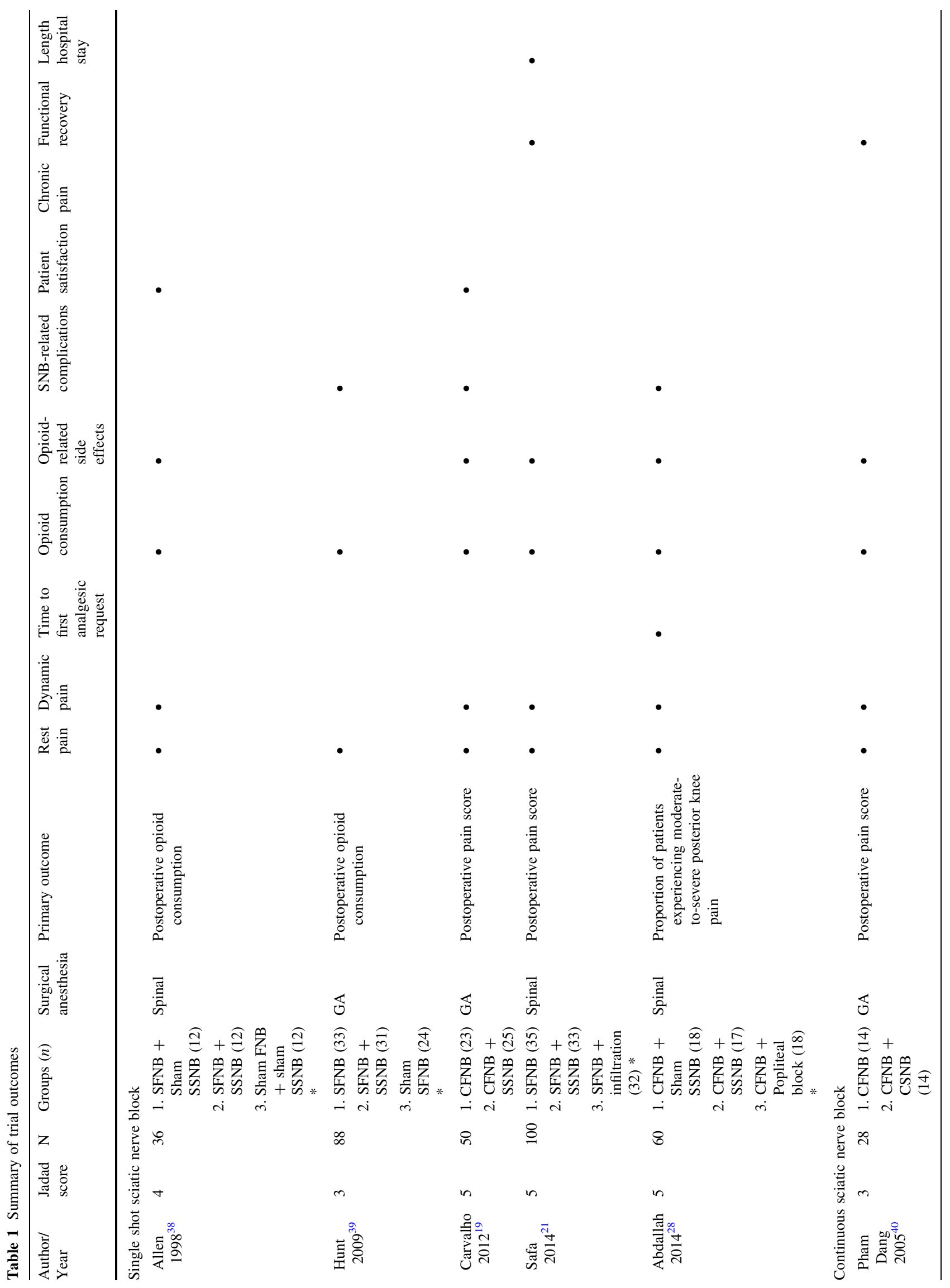




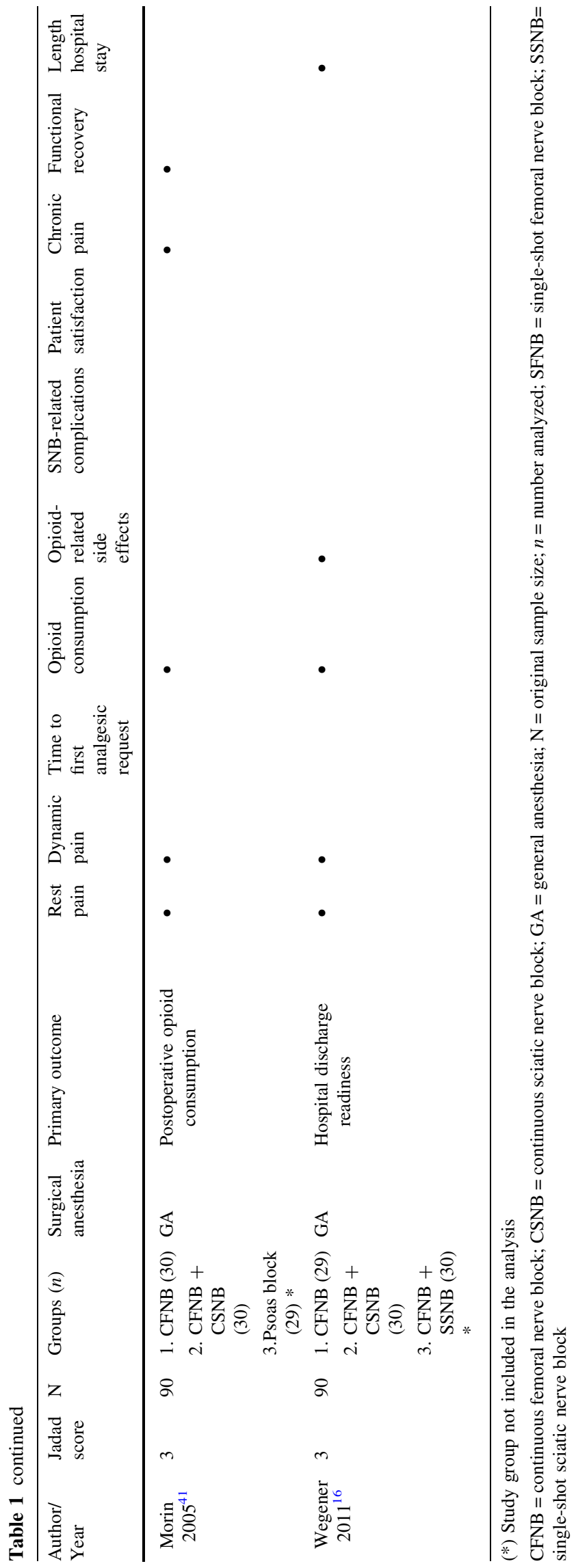

administered (e.g., intra-articular injection, epidural anesthesia, wound infiltration); (4) performed additional surgery on areas other than the knee joint (e.g., the ankle); (5) undertook knee procedures that did not include arthroplasty (e.g., cruciate ligament repair); (6) used local anesthetic adjuvants, except epinephrine, to prolong postoperative analgesia; and (7) included fewer than 10 study subjects to limit the possibility of detecting a treatment effect. In the absence of resources to support the translation of RCTs published in foreign languages, inclusion was limited to RCTs published in English, although English abstracts published in foreign-language journals were reviewed for potential relevance. Two authors (F.W.A., R.B.) separately evaluated the search results. Decisions on inclusion of qualifying studies were made by consensus between the two authors. The opinion of a third author (C.M.) was obtained when agreement could not be reached.

\section{Evaluation of methodological quality}

The Jadad score ${ }^{27}$ was used to evaluate the methodological quality of the retrieved trials. A score was separately assigned for the overall quality by two of the authors. The final quality score for each RCT was determined by consensus, although the opinion of a third author was obtained whenever agreement could not be reached. Quality scores were not used to exclude trials.

\section{Definition of relevant outcome data}

A standardized data collection form was developed and used to extract outcome results. When consensus could not be reached, discrepancies were resolved by re-examining the source data and asking the opinion of a third author. The authors also agreed pre hoc to refrain from extracting data from any RCTs that they had previously coauthored ${ }^{28}$ leaving this task to the third co-author. Extracted data included the name of the first author, publication year, the type of surgical anesthetic received, sample size and number of patients per study group, the nature of comparative groups, and the designated primary outcome. The analgesic outcomes extracted were the opioid consumption for two postoperative intervals: 0-24 $\mathrm{hr}$ and 24-48 hr. Pain severity scores were obtained at rest and with motion at two, four, eight, 12, 24, 36, and $48 \mathrm{hr}$ postoperatively. Also obtained were the time-to-first analgesic request (minutes); risk of opioid-related side effects (postoperative nausea and vomiting, pruritus, undesirable sedation); occurrence of block-related complications; patient satisfaction with analgesia received; extent of functional recovery (knee flexion, in degrees) four days following TKA; and time to hospital 


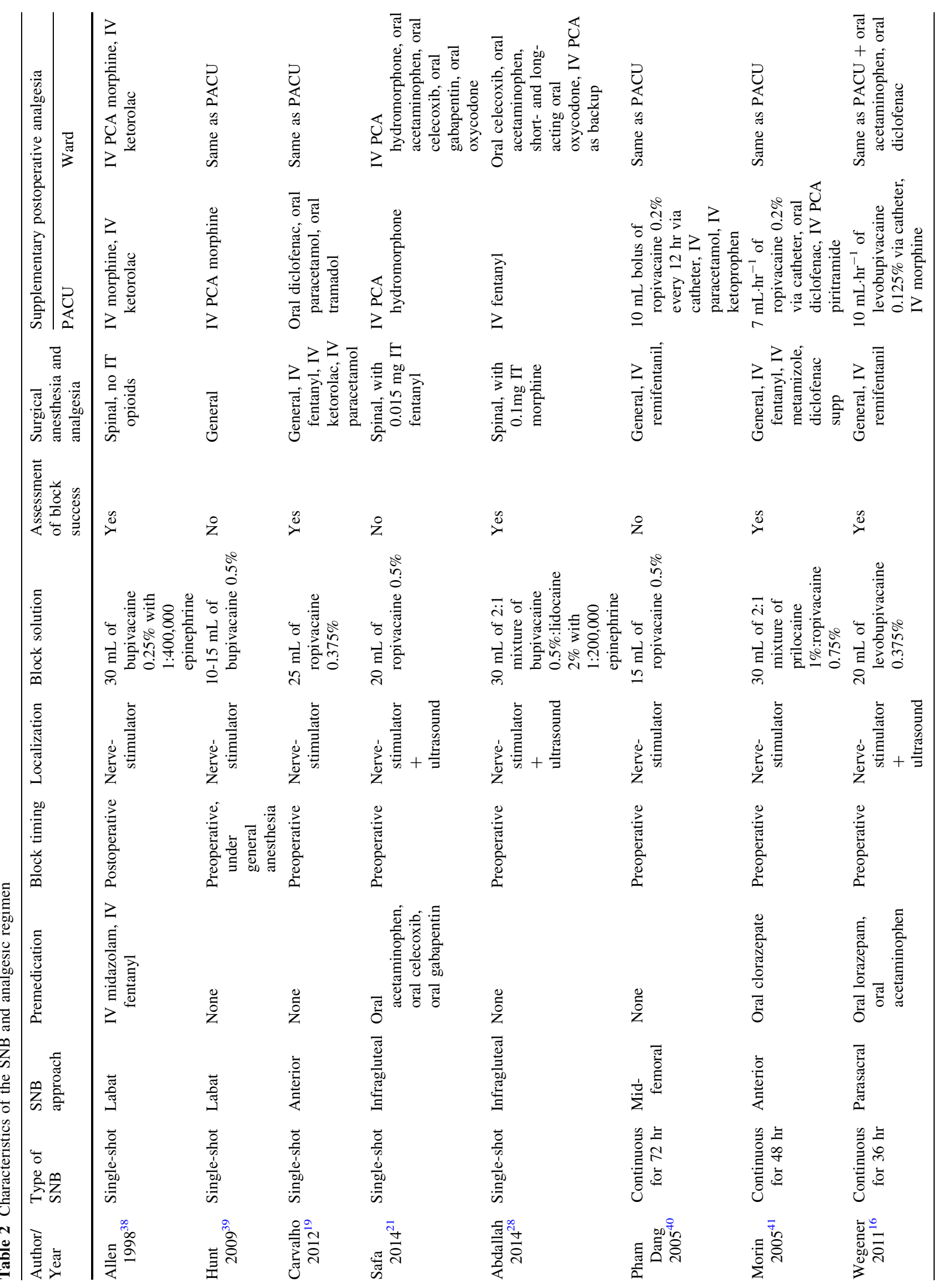


discharge (days). The cumulative opioid medications consumed during the first interval $(0-24 \mathrm{hr})$ postoperatively, converted into equi-analgesic doses of intravenous morphine, was selected as a primary outcome. All of the other analgesic outcomes were designated secondary outcomes. This choice of the primary outcome reflects the subjective nature of the pain severity scores and the influence of anxiety, catastrophisation, use of patientcontrolled analgesia, and aggressiveness of postoperative physiotherapy. ${ }^{29-31}$

For this review, verbal rating scale scores and pain numerical rating scale (NRS) scores were converted ${ }^{32}$ to 0 10 visual analogue scale (VAS) scores, where $10=$ worst pain imaginable, and $0=$ no pain. The amounts of all postoperative opioid analgesics consumed during the first $48 \mathrm{hr}$ were converted to equianalgesic doses of morphine. ${ }^{33}$ The degree of patient satisfaction with the pain relief at 24 hr postoperatively was reported as a VAS score $(10=$ most satisfied, $0=$ least satisfied).

\section{A priori identified sources of heterogeneity}

To explore the possible heterogeneity sources in our review, we a priori determined the clinical and design characteristics of RCTs that could potentially produce clinically important variations in the outcomes assessed. We subsequently evaluated the contribution of these characteristics to the heterogeneity of the results using subgroup analysis. Because evidence suggests that continuous SNB (i.e., catheter-based infusion via a pump) prolongs the duration of SNB analgesia ${ }^{16}$ we hypothesized that catheter use would introduce significant heterogeneity into our results. Consequently, we planned to analyze the outcome data separately according to whether single-shot sciatic nerve block (SSNB) or continuous sciatic nerve block (CSNB) had been used. Other sources of clinical heterogeneity that were explored via subgroup analysis included (1) surgical anesthetic (general vs spinal); (2) nature of the local anesthetic used for SNB (intermediate $v s$ long acting); (3) SNB guidance technique (nerve stimulator $v s$ nerve stimulator and ultrasonography); (4) type of FNB (single-shot $v s$ continuous); and (5) postoperative analgesic regimens used (multimodal $v s$ unimodal).

\section{Statistical analysis}

The data analyzed were primarily gathered from the tables in each of the source manuscripts. When data were not available in tables, we contacted the corresponding authors of the respective studies. If the authors did not reply or supply the outcome results needed, we resorted to abstracting results from the figures published in the source manuscripts as a secondary source of data. We also contacted the authors of published abstracts that met the eligibility criteria for further explanation regarding any missing details deemed relevant.

Dichotomous outcome results describing opioid-related side effects during a specified time interval were converted to frequencies $(\mathrm{n} / \mathrm{N})$. The single highest frequency was used to estimate the number of subjects who experienced a certain side effect at least once. Continuous outcome results were reported as the mean and standard deviation (SD). The median and interquartile range [IQR] was used as an estimate whenever the mean value was not explicitedly reported. ${ }^{34}$ In studies where the SD values were not provided in tables or graphs, the SD value was estimated as the value of the range/ $/ 4^{34}$ or the IQR/1.35, as appropriate $^{35}$ Where applicable, the $95 \%$ confidence interval (CI) was used as an estimate of the range, and the most extreme values were used to estimate the SD. When a specific outcome measure was reported more than once during a prespecified interval, we selected the most conservative available value.

\section{Meta-analysis}

The extracted results were separately entered into the systematic review statistical package (Revman 5.3, Cochrane Library, Oxford, England) and were crossexamined by two of the authors (F.W.A., R.B.). We employed meta-analytic statistics to pool and analyze the outcome results. Because clinically heterogeneous anesthetic techniques were used (e.g., general vs spinal anesthesia, varying doses of local anesthetics in SNB, different postoperative analgesic regimens), random effect modelling was selected. The weighted mean difference and 95\% CI were calculated for continuous outcomes, and the odds ratio (OR) and 95\% CI were calculated for dichotomous outcomes. Differences from the Control group were considered statistically significant when $P<$ 0.05 (two-sided), and when 0 and 1 were not included in the $95 \%$ CI for continuous and dichotomous outcomes, respectively.

We used the $\mathrm{I}^{2}$ statistic to evaluate the degree of heterogeneity among the RCTs reviewed. ${ }^{36}$ When heterogeneity was significant $\left(\mathrm{I}^{2}>50 \%\right)$, we explored the heterogeneity sources using subgroup analysis as per the preidentified potential sources of heterogeneity. ${ }^{37} \mathrm{An}$ additional post-hoc sensitivity analysis was planned to examine the effects of any of the preidentified factors where a meaningful subgroup analysis was not feasible as well as the effects of any additional factors identified during the data analysis. 


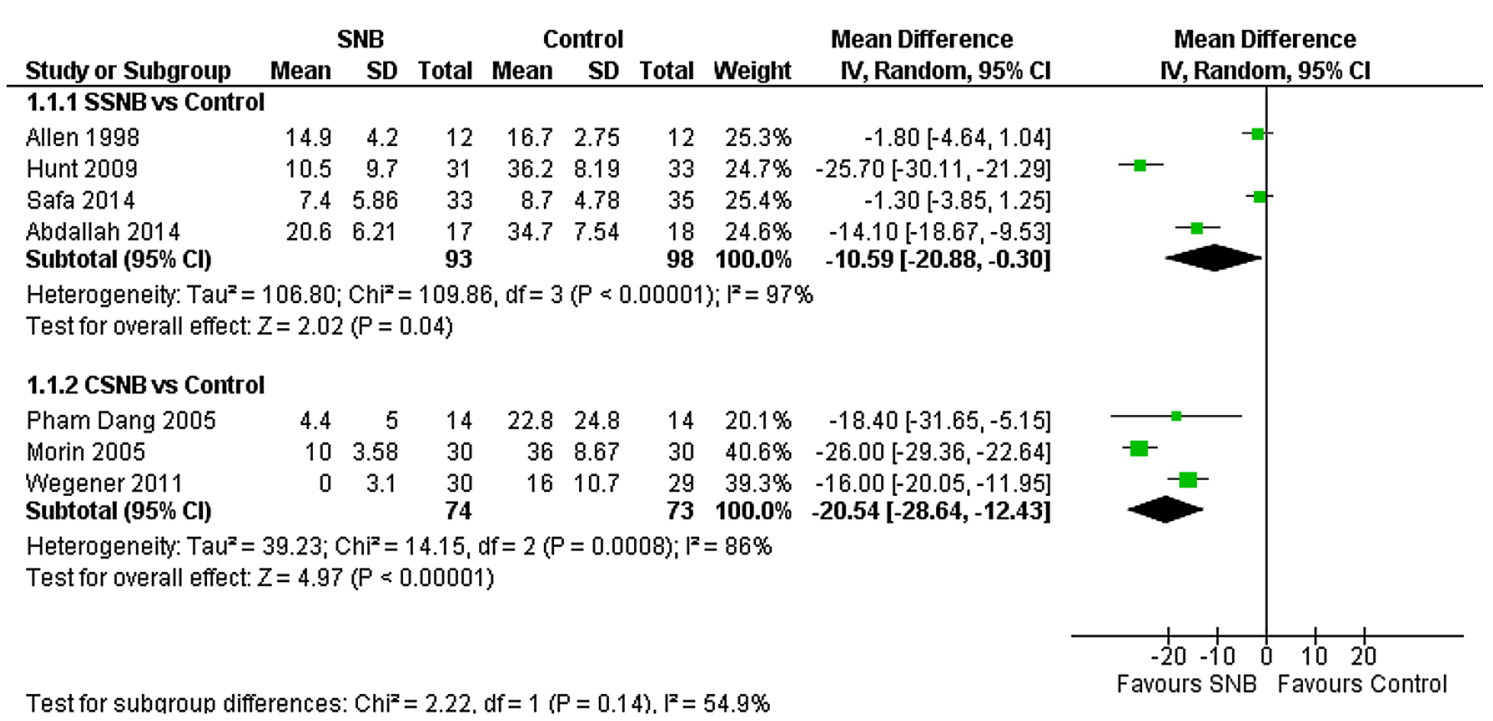

Fig. 2 Forest plots of intravenous morphine equivalent consumption during the first $24 \mathrm{hr}$ postoperatively $(0-24 \mathrm{hr}$ interval). The sample sizes, means, standard deviations, and pooled estimates of the mean difference are shown. The $95 \%$ confidence intervals (CI) are shown as

\section{Results}

Our literature search yielded 54 studies (Fig. 1), eight of which were published between January 1998 and March 2015 and met the eligibility criteria. ${ }^{16,19,21,28,38-41}$ One published abstract ${ }^{17}$ was excluded for lack of outcome results after contacting its authors. Five trials that compared SNB with various analgesic modalities, but lacked an appropriate FNB control group, were also excluded. ${ }^{15,18,20,22,23}$ A single relevant RCT comparing single-shot FNB to single-shot FNB + SNB was identified in the trial registries (clinical trials registry NCT02135120, relevant sample size $=30$ ), but it was still in the recruitment phase with no available outcome results. One other RCT published in a foreign language was excluded.

All reviewed trials were randomized, but only three reported appropriate randomization techniques. ${ }^{19,21,28}$ Five of the trials were double-blinded, ${ }^{19,21,28,38,39}$ but only four of them ${ }^{19,21,28,38}$ reported appropriate blinding techniques. Three $^{19,21,28}$ of the eight trials achieved a quality score of 5 out of 5 (i.e., they were randomized, double-blinded, reported appropriate blinding and randomization techniques, and described complete patient disposition. The median [IQR] and range of the methodological quality score for the eight trials included in this review was 3.5 (35). None of the RCTs was excluded based on its methodological quality scores or because the number of patients was fewer than ten. Table 1 describes the methodological quality and the risk of bias of the trials that were included. lines for individual studies and as diamonds for pooled estimates. $\mathrm{CSNB}=$ continuous sciatic nerve block; SSNB $=$ single-shot sciatic nerve block

The data from 386 patients were used in our metaanalysis, which included 192 patients in the SNB group and 194 in the Control group. The characteristics and outcomes sought in each trial are presented in Table 1. Each of the eight RCTs included analgesic outcomes, including analgesic consumption and pain severity scores. An SSNB was used in five trials ${ }^{19,21,28,38,39}$ and a CSNB in two. $^{40,41}$ Although both techniques were used in a single trial, ${ }^{16}$ only the CSNB group was included in the analysis. The local anesthetic solution, volume, localization technique, and delivery method for all SNBs performed are summarized in Table 2. One trial included two patient groups that underwent $\mathrm{SNB},{ }^{28}$ but only one group met the eligibility criteria.

Analgesic consumption for the $0-24 \mathrm{hr}$ interval

Data relating to postoperative analgesic consumption during the 0-24 hr interval were available from seven RCTs, ${ }^{16,21,28,38-41}$ which included a total of 338 patients (167 patients in the SNB group and 171 in the Control group). Compared to no Controls, both the SSNB and CSNB reduced the weighted mean difference [95\% CI] postoperative intravenous morphine equivalent consumption by $10.6[-20.9$ to -0.3$] \mathrm{mg}(P=0.042)$ and 20.5 [ -28.6 to -12.4$] \mathrm{mg}(P<0.001)$, respectively, during the 0-24 hr interval postoperatively (Fig. 2).

The primary outcome results were characterized by high heterogeneity for the SSNB and CSNB subgroups, with $\mathrm{I}^{2}=97 \%(P<0.001)$ and $\mathrm{I}^{2}=86 \%(P<0.001)$, 
Table 3 Summary of outcomes results

\begin{tabular}{|c|c|c|c|c|c|c|c|c|}
\hline Outcome & Subgroup & $\begin{array}{l}\text { Studies } \\
\text { included }\end{array}$ & $\begin{array}{l}\mathrm{SNB} \\
\text { Mean or } \\
\mathrm{n} / \mathrm{N}\end{array}$ & $\begin{array}{l}\text { Control } \\
\text { Mean or } \\
\mathrm{n} / \mathrm{N}\end{array}$ & $\begin{array}{l}\text { OR or WMD }[95 \% \\
\text { Confidence } \\
\text { Interval] }\end{array}$ & $\begin{array}{l}P \text {-value for } \\
\text { statistical } \\
\text { significance }\end{array}$ & $\begin{array}{l}P \text {-value for } \\
\text { heterogeneity }\end{array}$ & $\begin{array}{l}\mathrm{I}^{2} \text { Test for } \\
\text { heterogeneity }\end{array}$ \\
\hline \multirow{2}{*}{$\begin{array}{l}\text { Cumulative morphine } \\
\text { consumption for } 0-24 \mathrm{hr} \\
(\mathrm{mg})\end{array}$} & SSNB & $21,28,38,39$ & 11.8 & 23.7 & $\begin{array}{l}-10.59[-20.88 \text { to } \\
\quad-0.30]\end{array}$ & 0.04 & $<0.00001$ & $97 \%$ \\
\hline & CSNB & $16,40,41$ & 4.9 & 25.5 & $\begin{array}{l}-20.54[-28.64 \text { to } \\
-12.43]\end{array}$ & $<0.00001$ & 0.0008 & $86 \%$ \\
\hline \multirow{2}{*}{$\begin{array}{l}\text { Cumulative morphine } \\
\text { consumption for } 24-48 \\
\mathrm{hr}(\mathrm{mg})\end{array}$} & SSNB & 38 & 13.9 & 9.8 & $4.10[2.17$ to 6.03$]$ & $<0.0001$ & N/A & N/A \\
\hline & CSNB & 16,41 & 3.5 & 4.07 & $\begin{array}{l}-0.82[-2.69 \text { to } \\
1.04]\end{array}$ & 0.39 & 0.69 & $0 \%$ \\
\hline \multirow[t]{2}{*}{ Rest pain at $2 \mathrm{hr}(\mathrm{cm})$} & SSNB & $19,28,38,39$ & 2.6 & 4.4 & $\begin{array}{l}-1.94[-3.83 \text { to } \\
-0.04]\end{array}$ & 0.04 & $<0.00001$ & $94 \%$ \\
\hline & CSNB & $16,40,41$ & 0.13 & 4.8 & $\begin{array}{l}-4.29[-6.45 \text { to } \\
-2.14]\end{array}$ & $<0.0001$ & $<0.00001$ & $94 \%$ \\
\hline \multirow[t]{2}{*}{ Rest pain at $4 \mathrm{hr}(\mathrm{cm})$} & SSNB & $21,28,38,39$ & 2.7 & 3.7 & $\begin{array}{l}-1.15[-2.28 \text { to } \\
-0.03]\end{array}$ & 0.04 & $<0.00001$ & $94 \%$ \\
\hline & CSNB & 40,41 & 0.3 & 3.1 & $\begin{array}{l}-2.84[-3.36 \text { to } \\
\quad-2.33]\end{array}$ & $<0.00001$ & 0.82 & $0 \%$ \\
\hline \multirow[t]{2}{*}{ Rest pain at $8 \mathrm{hr}(\mathrm{cm})$} & SSNB & $21,28,38,39$ & 3.0 & 3.8 & $\begin{array}{l}-0.68[-1.25 \text { to } \\
-0.10]\end{array}$ & 0.02 & $<0.001$ & $82 \%$ \\
\hline & CSNB & $16,40,41$ & 0.2 & 3.5 & $\begin{array}{l}-3.18[-4.09 \text { to } \\
-2.28]\end{array}$ & $<0.00001$ & 0.02 & $74 \%$ \\
\hline \multirow[t]{2}{*}{ Rest pain at $12 \mathrm{hr}(\mathrm{cm})$} & SSNB & $19,21,28$ & 1.96 & 2.61 & $\begin{array}{l}-0.64[-1.52 \text { to } \\
0.31]\end{array}$ & 0.19 & 0.05 & $66 \%$ \\
\hline & CSNB & 40,41 & 0.24 & 3.18 & $\begin{array}{l}-2.95[-3.50 \text { to } \\
-2.40]\end{array}$ & $<0.00001$ & 0.96 & $0 \%$ \\
\hline \multirow[t]{2}{*}{ Rest pain at $24 \mathrm{hr}(\mathrm{cm})$} & SSNB & $19,21,28,38,39$ & 3.0 & 2.9 & $\begin{array}{l}-0.05[-0.88 \text { to } \\
0.79]\end{array}$ & 0.91 & $<0.00001$ & $90 \%$ \\
\hline & CSNB & $16,40,41$ & 0.2 & 2.3 & $\begin{array}{l}-2.02[-2.89 \text { to } \\
-1.15]\end{array}$ & $<0.00001$ & 0.05 & $65 \%$ \\
\hline \multirow[t]{2}{*}{ Rest pain at $36 \mathrm{hr}(\mathrm{cm})$} & SSNB & $21,38,39$ & 2.7 & 2.7 & $\begin{array}{l}0.36[-0.69 \text { to } \\
1.41]\end{array}$ & 0.5 & $<0.00001$ & $95 \%$ \\
\hline & CSNB & 16 & 0 & 1.3 & $\begin{array}{l}-1.28[-2.15 \text { to } \\
-0.41]\end{array}$ & 0.004 & N/A & N/A \\
\hline \multirow[t]{2}{*}{ Rest pain at $48 \mathrm{hr}(\mathrm{cm})$} & SSNB & $21,38,39$ & 2.0 & 1.9 & $\begin{array}{l}0.13[-0.02 \text { to } \\
\quad 0.29]\end{array}$ & 0.1 & 0.31 & $14 \%$ \\
\hline & CSNB & $16,40,41$ & 1.0 & 1.5 & $\begin{array}{l}-0.24[-0.61 \text { to } \\
\quad 0.14]\end{array}$ & 0.22 & 0.36 & $2 \%$ \\
\hline \multirow[t]{2}{*}{ Dynamic pain at $2 \mathrm{hr}(\mathrm{cm})$} & SSNB & 28 & 2.2 & 3.7 & $\begin{array}{l}-1.45[-2.70 \text { to } \\
\quad-0.20]\end{array}$ & 0.02 & N/A & N/A \\
\hline & CSNB & 41 & 2.5 & 5.1 & $\begin{array}{l}-2.56[-3.44 \text { to } \\
\quad-1.68]\end{array}$ & $<0.00001$ & N/A & N/A \\
\hline \multirow[t]{2}{*}{ Dynamic pain at $4 \mathrm{hr}(\mathrm{cm})$} & SSNB & 21,28 & 2.2 & 5.0 & $\begin{array}{l}-3.24[-6.20 \text { to } \\
-0.29]\end{array}$ & 0.03 & $<0.00001$ & $95 \%$ \\
\hline & CSNB & 41 & 2.5 & 5.1 & $\begin{array}{l}-2.56[-3.44 \text { to } \\
-1.68]\end{array}$ & $<0.00001$ & N/A & N/A \\
\hline \multirow[t]{2}{*}{ Dynamic pain at $8 \mathrm{hr}(\mathrm{cm})$} & SSNB & 21,28 & 4.2 & 4.6 & $\begin{array}{l}-0.52[-0.78 \text { to } \\
-0.26]\end{array}$ & $<0.0001$ & 0.7 & $0 \%$ \\
\hline & CSNB & 41 & 2.5 & 5.1 & $\begin{array}{l}-2.56[-3.44 \text { to } \\
-1.68]\end{array}$ & $<0.00001$ & N/A & N/A \\
\hline $\begin{array}{l}\text { Dynamic pain at } 12 \mathrm{hr} \\
(\mathrm{cm})\end{array}$ & SSNB & $19,21,28$ & 3.33 & 4.2 & $\begin{array}{l}-0.7[-1.49 \text { to } \\
0.08]\end{array}$ & 0.08 & 0.21 & $35 \%$ \\
\hline
\end{tabular}


Table 3 continued

\begin{tabular}{|c|c|c|c|c|c|c|c|c|}
\hline Outcome & Subgroup & $\begin{array}{l}\text { Studies } \\
\text { included }\end{array}$ & $\begin{array}{l}\text { SNB } \\
\text { Mean or } \\
n / N\end{array}$ & $\begin{array}{l}\text { Control } \\
\text { Mean or } \\
\mathrm{n} / \mathrm{N}\end{array}$ & $\begin{array}{l}\text { OR or WMD }[95 \% \\
\text { Confidence } \\
\text { Interval] }\end{array}$ & $\begin{array}{l}P \text {-value for } \\
\text { statistical } \\
\text { significance }\end{array}$ & $\begin{array}{l}P \text {-value for } \\
\text { heterogeneity }\end{array}$ & $\begin{array}{l}\mathrm{I}^{2} \text { Test for } \\
\text { heterogeneity }\end{array}$ \\
\hline & CSNB & 41 & 2.54 & 5.1 & $\begin{array}{l}-2.56[-3.44 \text { to } \\
-1.68]\end{array}$ & $<0.00001$ & N/A & N/A \\
\hline \multirow{2}{*}{$\begin{array}{l}\text { Dynamic pain at } 24 \mathrm{hr} \\
\quad(\mathrm{cm})\end{array}$} & SSNB & $19,21,28,38$ & 4.9 & 4.8 & $0.29[0.04$ to 0.55$]$ & 0.02 & 0.59 & $0 \%$ \\
\hline & CSNB & 16,41 & 1.3 & 4.1 & $\begin{array}{l}-2.74[-3.43 \text { to } \\
-2.05]\end{array}$ & $<0.00001$ & 0.52 & $0 \%$ \\
\hline \multirow[t]{2}{*}{$\begin{array}{l}\text { Dynamic pain at } 36 \mathrm{hr} \\
(\mathrm{cm})\end{array}$} & SSNB & 21,38 & 3.8 & 3.8 & $\begin{array}{l}0.03[-0.19 \text { to } \\
0.25]\end{array}$ & 0.79 & 0.63 & $0 \%$ \\
\hline & CSNB & 16 & 2 & 3.3 & $\begin{array}{l}-1.29[-2.28 \text { to } \\
-0.30]\end{array}$ & 0.01 & N/A & N/A \\
\hline \multirow{2}{*}{$\begin{array}{l}\text { Dynamic pain at } 48 \mathrm{hr} \\
\quad(\mathrm{cm})\end{array}$} & SSNB & 21,38 & 3.8 & 3.2 & $0.70[0.09$ to 1.30$]$ & 0.02 & 0.01 & $84 \%$ \\
\hline & CSNB & $16,40,41$ & 2.6 & 3.8 & $\begin{array}{l}-1.07[-2.06 \text { to } \\
-0.08]\end{array}$ & 0.03 & 0.12 & $53 \%$ \\
\hline \multirow{2}{*}{$\begin{array}{l}\text { Incidence of PONV at } 24 \\
\mathrm{hr}(\mathrm{n} / \mathrm{N})\end{array}$} & SSNB & 28,38 & $5 / 12$ & $3 / 12$ & $0.56[0.04$ to 7.12$]$ & 0.66 & 0.03 & $80 \%$ \\
\hline & CSNB & 40 & $2 / 14$ & $9 / 14$ & $0.09[0.01$ to 0.59$]$ & 0.01 & N/A & N/A \\
\hline \multirow{2}{*}{$\begin{array}{l}\text { Incidence of pruritus at } 24 \\
\mathrm{hr}(\mathrm{n} / \mathrm{N})\end{array}$} & SSNB & 38 & $2 / 12$ & $2 / 12$ & $1.00[0.12$ to 8.56$]$ & 1.0 & N/A & N/A \\
\hline & CSNB & N/A & N/A & N/A & N/A & N/A & N/A & N/A \\
\hline \multirow{2}{*}{$\begin{array}{l}\text { Incidence of sedation at } \\
\qquad 24 \mathrm{hr}(\mathrm{n} / \mathrm{N})\end{array}$} & SSNB & 38 & $2 / 12$ & $0 / 12$ & $0.17[0.01$ to 3.90$]$ & 0.27 & N/A & N/A \\
\hline & CSNB & N/A & N/A & N/A & N/A & N/A & N/A & N/A \\
\hline \multirow[t]{2}{*}{$\begin{array}{l}\text { Block-related } \\
\text { complications }\end{array}$} & SSNB & $19,28,39$ & $2 / 69$ & $0 / 71$ & $\begin{array}{c}5.97[0.27 \text { to } \\
133.87]\end{array}$ & 0.26 & N/A & N/A \\
\hline & CSNB & N/A & N/A & N/A & N/A & N/A & N/A & N/A \\
\hline \multirow{2}{*}{$\begin{array}{l}\text { Functional recovery at } 4 \\
\text { days (flexion in } \\
\text { degrees) }\end{array}$} & SSNB & N/A & N/A & N/A & N/A & N/A & N/A & N/A \\
\hline & CSNB & $16,40,41$ & 77.7 & 64.8 & $\begin{array}{l}11.74[-2.64 \text { to } \\
26.12]\end{array}$ & 0.11 & $<0.00001$ & $93 \%$ \\
\hline \multirow[t]{2}{*}{$\begin{array}{l}\text { Time-to-hospital } \\
\text { discharge (days) }\end{array}$} & SSNB & 21 & 4.3 & 4.3 & $\begin{array}{l}0.00[-0.39 \text { to } \\
0.39]\end{array}$ & 1 & N/A & N/A \\
\hline & CSNB & 16 & 4 & 4 & $\begin{array}{l}0.00[-1.59 \text { to } \\
1.59]\end{array}$ & 1 & N/A & N/A \\
\hline
\end{tabular}

CSNB = continuous sciatic nerve block; N/A = not applicable; OR = odds ratio; PONV = postoperative nausea and vomiting; SSNB = single-shot sciatic nerve block; WMD = weighted mean difference

respectively. Alternative subgroup analysis showed that the patients undergoing SNB continued to have reduced opioid consumption during the 0-24 hr interval compared with that of the Control group. Specifically, the reduction in cumulative postoperative morphine equivalent consumption was $22.1[-27.8$ to -16.3$] \mathrm{mg}(P<0.001)$, $\mathrm{I}^{2}=82 \%$ and $6.5[-12.0$ to -1.1$] \mathrm{mg}(P<0.001), \mathrm{I}^{2}=$ $92 \%$ for the general anesthesia vs spinal anesthesia subgroups, respectively; $17.9[-32.7$ to -3.1$] \mathrm{mg}(P=$ $0.022), \mathrm{I}^{2}=98 \%$ and $10.9[-20.7$ to -1.1$] \mathrm{mg}(P=0.011)$, $\mathrm{I}^{2}=96 \%$ for the nerve stimulator $v s$ nerve stimulator and ultrasonography, respectively; 12.7 [-22.2, to -3.2$] \mathrm{mg}(P$
$<0.001), \mathrm{I}^{2}=98 \%$ and $18.8[-25.5$ to -12.0$] \mathrm{mg}(P<$ $0.001), \mathrm{I}^{2}=87 \%$ for the single-shot FNB vs continuous FNB, respectively. No trials used intermediate-acting local anesthetics, and only one $\mathrm{e}^{38,39}$ used unimodal postoperative analgesic regimens, precluding a meaningful subgroup analysis for the respective a priori identified sources of heterogeneity. The test for subgroup differences was statistically significant for the general anesthesia $v s$ spinal anesthesia subgroup analysis $(P<0.001)$ but not for the nerve stimulator $v s$ nerve stimulator and ultrasonography analysis $(P=0.421)$ or for the single-shot FNB vs continuous FNB analysis $(P=0.212)$. This subgroup 


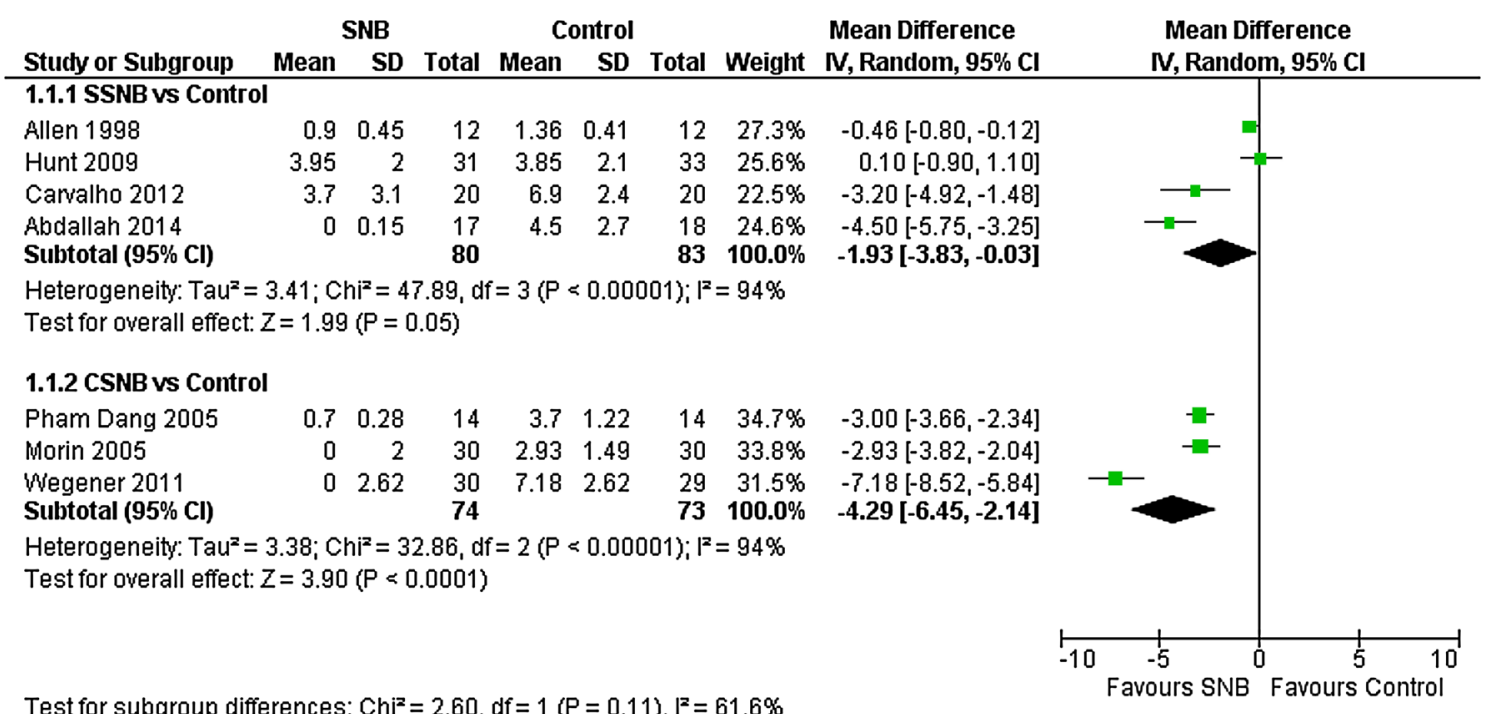

Fig. 3 Forest plots of pain severity at rest using visual analogue scale (VAS) pain scores at $2 \mathrm{hr}$. The sample sizes, means, standard deviations, and pooled estimates of the mean difference are shown. The $95 \%$ confidence intervals (CI) are shown as lines for individual

difference suggests that patients who undergo TKA under general anesthesia may benefit more from SNB than those who receive a spinal anesthetic.

Analgesic consumption during the $24-48 \mathrm{hr}$ interval

Only three studies reported analgesic consumption during the 24-48 hr interval. Whereas one study ${ }^{38}$ suggested that the cumulative postoperative opioid analgesic (intravenous morphine equivalent) consumption during the 24-48 hr interval was greater by $4.1[2.2$ to 6.0$] \mathrm{mg}(P<0.001)$ in the SSNB subgroup compared to that of the Controls (Table 3), the remaining two studies ${ }^{16,41}$ indicated that the difference was not significant for the CSNB subgroup.

Pain at rest

Compared with the Controls, SSNB decreased the pain severity at rest at the two-, four-, and eight-hour checkpoints postoperatively by $1.9[-3.8$ to 0.0$] \mathrm{cm}(P=$ $0.041), 1.2[-2.3$ to 0$] \mathrm{cm}(P=0.04)$, and $0.7[-1.3$ to $-0.1] \mathrm{cm}(P=0.023)$, respectively (Table 3$)$. The eighthour assessment of pain severity at rest was the last point at which we observed a significant reduction in pain attributed to SSNB. Figures 3 and 4 show forest plots of the weighted mean difference in pain at rest (VAS scores) at 2 and $8 \mathrm{hr}$, respectively.

Compared with the Controls, CSNB decreased pain severity at rest two, four, eight, 12, 24, and $36 \mathrm{hr}$ postoperatively by $4.3[-6.4$ to -2.1$] \mathrm{cm}(P<0.001)$, $2.8[-3.4$ to -2.3$] \mathrm{cm}(P<0.001), 3.2[-4.1$ to -2.3$] \mathrm{cm}$ studies and as diamonds for pooled estimates. CSNB $=$ continuous sciatic nerve block; SNB = sciatic nerve block; SSNB = single-shot sciatic nerve block

$(P<0.001), 3.0[-3.5$ to -2.4$] \mathrm{cm}(P<0.001), 2.0[-2.9$ to -1.2$] \mathrm{cm}(P<0.001)$, and $1.3[-2.2$ to -0.4$] \mathrm{cm}(P=$ 0.004 ), respectively (Table 3 ). The 36-hr assessment of pain severity at rest was the last point at which we observed a significant reduction in pain attributed to CSNB. The changes in pain at rest (VAS scores, weighted mean difference) for the Controls and the CSNB subgroup over time are shown in Fig. 4.

Pain with movement

Compared with the Controls, SSNB decreased pain severity with movement at two, four, and eight hours postoperatively by $1.5[-2.7$ to -0.2$] \mathrm{cm}(P=0.023), 3.2$ [ -6.2 to -0.3$] \mathrm{cm}(P=0.034)$, and $0.5[-0.8$ to -0.3$] \mathrm{cm}$ $(P<0.001)$, respectively (Table 3$)$. We observed no benefit attributable to SSNB beyond eight hours. In contrast, CSNB reduced pain with movement at all measured time points, including $48 \mathrm{hr}$, compared with that in the Control group (Table 3).

\section{Opioid-related side effects}

The frequency of opioid-related side effects was selected as an outcome by a limited number of trials. Three RCTs two in the SNB subgroup ${ }^{28,38}$ and one in the CSNB subgroup $^{40}$ - reported the incidence of postoperative nausea and vomiting, and only one RCT in the SNB subgroup ${ }^{38}$ reported the incidence of pruritus and sedation. The frequency of opioid-related side effects in the SNB subgroup did not differ from that in the Controls. 


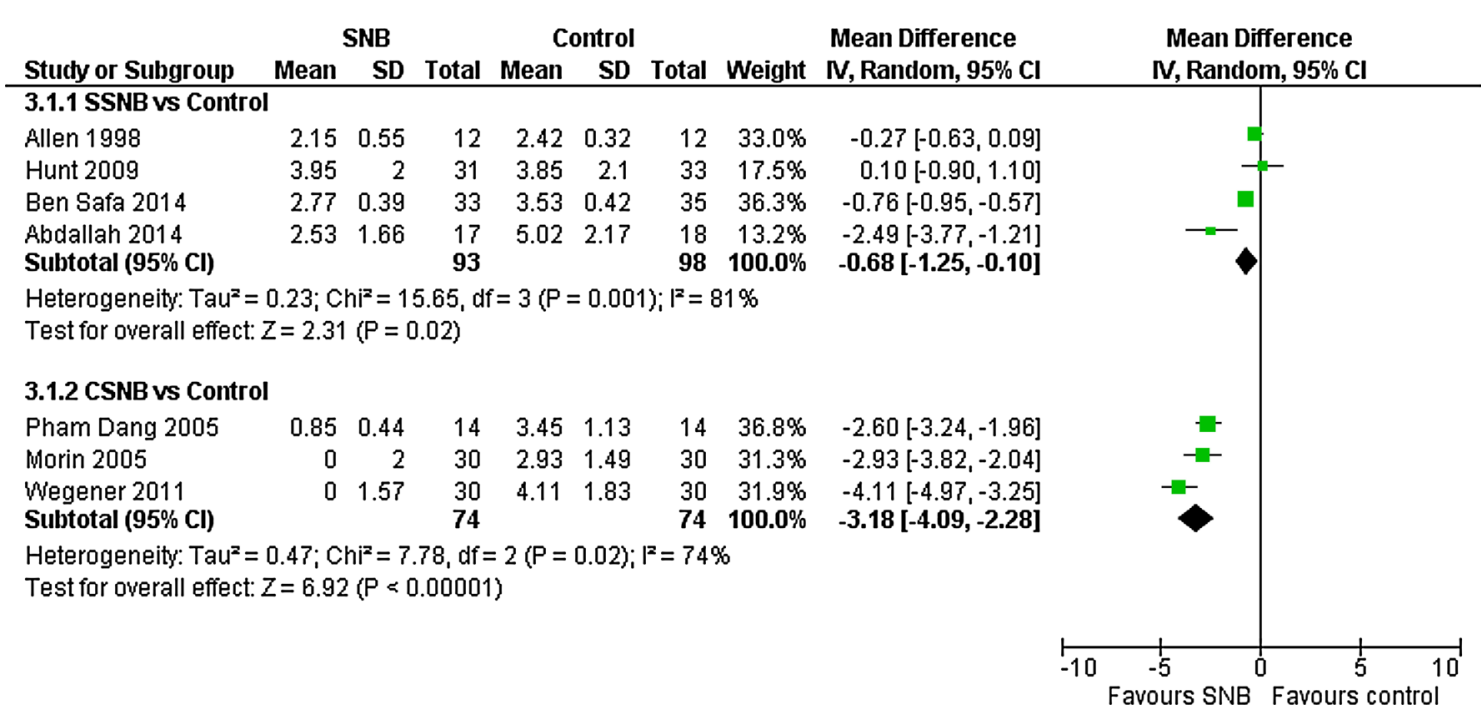

Fig. 4 Forest plots of the pain severity at rest using visual analogue scale (VAS) pain scores at $8 \mathrm{hr}$. The sample sizes, means, standard deviations, and pooled estimates of the mean difference are shown. The $95 \%$ confidence intervals (CI) are shown as lines for individual

However, CSNB reduced the odds of postoperative nausea and vomiting at $24 \mathrm{hr}$ by $93 \%$ (OR [95\% CI], 0.09 [0.01 to 0.59], $P=0.011$ ) compared with the Controls (Table 3). Inconsistent reporting precluded evaluating the effect of CSNB on pruritus and sedation.

\section{Other outcomes}

The frequency of block-related complications was reported only in trials with an SSNB subgroup (Table 3). Two patients were reported to experience transient paresthesias lasting one week, ${ }^{28}$ but we found no difference in blockrelated complications when the SSNB group was compared with the Controls. Functional recovery was reported only in trials with a CSNB subgroup (Table 3). We found no difference in functional recovery when the CSNB group was compared with the Controls (Fig. 5). In addition, we found no differences in the discharge time when SNB whether SSNB or CSNB - were compared with the Controls (Table 3). We were unable to examine quantitatively the remaining secondary outcomes (time to first analgesic request, patient satisfaction with pain relief) because of inconsistent reporting and the heterogeneous assessment procedures in the source trials.

We performed a post hoc alternative subgrouping and sensitivity analysis to explore the potential sources of the heterogeneity of the results. Alternative subgrouping by incorporating the SSNB arm of the study by Wegener et al. ${ }^{16}$ (a three-arm RCT that included SSNB, CSNB, and Control groups) in the analysis, instead of the CSNB arm, maintained the significance of results but reduced the heterogeneity of the CSNB subgroup, with opioid studies and as diamonds for pooled estimates. CSNB = continuous sciatic nerve block; SNB = sciatic nerve block; SSNB = single-shot sciatic nerve block

consumption reduced by $11.2[-19.9$ to -2.6$] \mathrm{mg}(P=$ $0.013), \mathrm{I}^{2}=97 \%$ and $25.0[-30.0$ to -20.0$] \mathrm{mg}(P<$ $0.001), \mathrm{I}^{2}=16 \%$ in the SSNB and CSNB subgroups, respectively.

Post-hoc sensitivity analysis was used to examine the impact of several factors on the results' heterogeneity, including the methodological quality scores (i.e., inappropriate blinding), mixing epinephrine with local anesthetics, timing of SNB, not assessing block success, and using unimodal $v s$ multimodal postoperative analgesia. Eliminating the results of the four RCTs ${ }^{16,39-41}$ that achieved a Jadad score of 3 rendered the SSNB subgroup results insignificant, with a weighted mean difference in opioid consumption of $5.4[-12.0$ to 1.1$] \mathrm{mg}(P=0.142)$. Also, all of the RCTs in the CSNB subgroup were eliminated. Furthermore, removing the data of the two $\mathrm{RCTs}^{28,38}$ that mixed their local anesthetic solution with epinephrine rendered the SSNB subgroup results insignificant, with a weighted mean difference in opioid consumption of 13.4 [ -37.3 to 10.5$] \mathrm{mg}(P=0.274)$ and $20.5[-28.6$ to -12.4$] \mathrm{mg}(P<0.001), \mathrm{I}^{2}=86 \%$ for the SSNB and CSNB subgroups, respectively. Additionally, removing the results of the single $\mathrm{RCT}^{38}$ that performed SNB postoperatively rendered the SSNB subgroup results insignificant, with a weighted mean difference in opioid consumption of 13.6 [ -28.6 to 1.4$] \mathrm{mg}(P=0.082)$ and 20.5 [ -28.6 to -12.4$] \mathrm{mg}(P<0.001), \mathrm{I}^{2}=86 \%$ for the SSNB and CSNB subgroups, respectively. Moreover, excluding the data of the three RCTs ${ }^{21,39,40}$ that did not perform block assessment to confirm SNB success rendered the SSNB subgroup results insignificant, with a weighted mean difference in opioid consumption of 7.8 


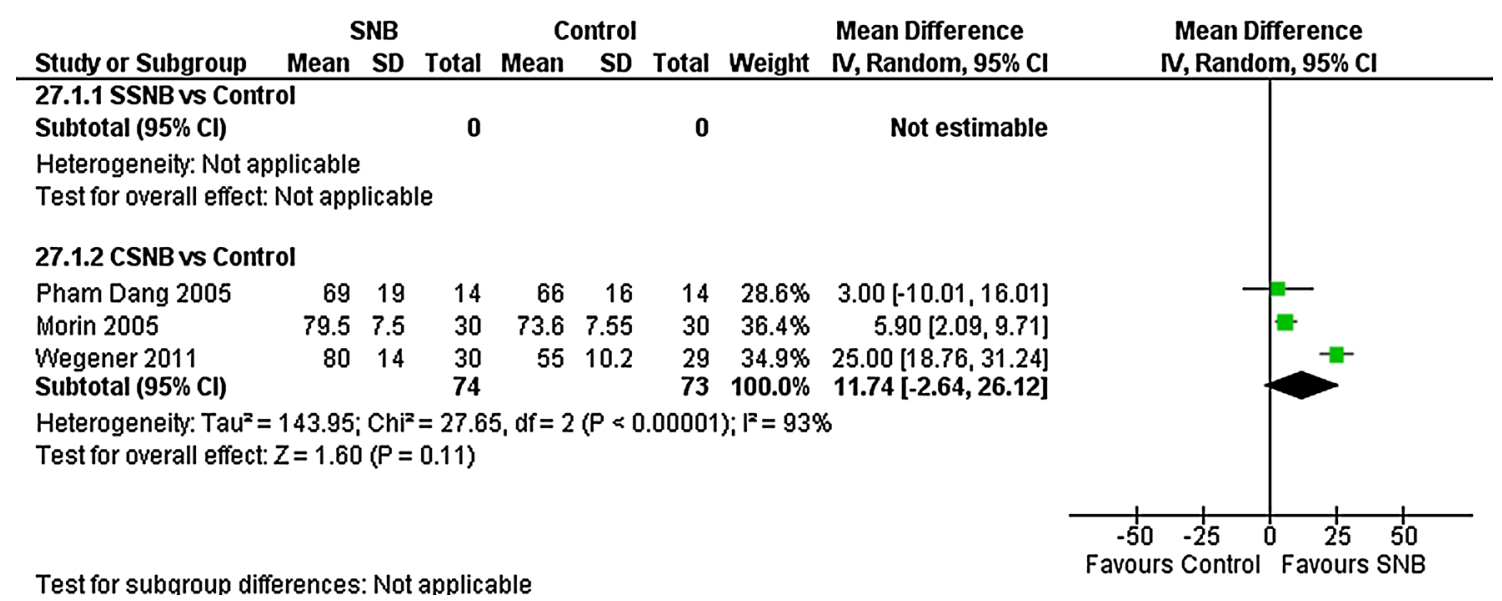

Fig. 5 Forest plots of postoperative functional recovery (range of motion in degrees). The sample sizes, means, standard deviations, and pooled estimates of the mean difference are shown. The $95 \%$ confidence intervals (CI) are shown as lines for individual studies

[ -19.9 to 4.2$] \mathrm{mg}(P=0.232)$ and $21.1[-30.9$ to -11.3$]$ $(P<0.001), \mathrm{I}^{2}=93 \%$ for the SSNB and CSNB subgroups, respectively. Finally, eliminating the data of the two RCTs $^{38,39}$ that used unimodal postoperative analgesia rendered the SSNB subgroup results insignificant, with a weighted mean difference in opioid consumption of 7.6 [-20.1 to 5.0$] \mathrm{mg}(P=0.244)$ and $20.5[-28.6$ to -12.4$]$ $\mathrm{mg}(P<0.001), \mathrm{I}^{2}=86 \%$ for the SSNB and CSNB subgroups, respectively. As such, our post hoc analysis failed to reduce the extent of heterogeneity in the source data.

\section{Discussion}

This meta-analysis suggests that adding SNB to FNB can improve analgesia following TKA by reducing postoperative opioid consumption up to $24 \mathrm{hr}$, with a larger reduction associated with CSNB than SSNB. The magnitude of this improvement may be greater in patients who undergo TKA under a general anesthetic compared with spinal anesthesia. Unfortunately, the heterogeneity and intrinsic limitations of the source data reviewed limit the strength of our findings. The present quantitative review nonetheless points to level $1 \mathrm{a}-$ (minus) evidence $^{42}$ (i.e., representing a systematic review with significant heterogeneity) in support of the SNB, a notable improvement from the level $2 \mathrm{a}-$ evidence supporting SNB that we observed in our earlier qualitative review of the literature. ${ }^{14}$

Our results also suggest that SSNB can reduce pain at rest and during movement up to eight hours postoperatively, whereas CSNB can reduce pain at rest up to $36 \mathrm{hr}$ and pain with movement up to $48 \mathrm{hr}$. The relative superior analgesia associated with CSNB

and as diamonds for pooled estimates. $\mathrm{CSNB}=$ continuous sciatic nerve block; SNB = sciatic nerve block; SSNB = single-shot sciatic nerve block

compared with SSNB during the first eight hours postoperatively may well be attributable to the extensive multi-modal analgesic regimen used in CSNB trials. Also, the increase in opioid consumption and opioid-related side effects during the 24-48 $\mathrm{hr}$ interval associated with SSNB compared with CSNB may be at least partially explained by the "rebound pain" phenomenon that has been described in TKA patients when the effect of the nerve block dissipates. ${ }^{43}$ Additional SNB benefits may include a reduction in the frequency of postoperative nausea and vomiting in patients who underwent CSNB. Importantly, our results also signal no delay in functional recovery or hospital discharge associated with SNB for TKA. Finally, the relatively small number of patients reviewed herein $(n$ =338), coupled with the inconsistent assessment of blockrelated complications, preclude any meaningful conclusions regarding SNB safety. Consequently, concerns regarding SNB-related nerve injury, masking of surgical injury to the peroneal nerve, and delayed mobilization still apply. ${ }^{44,45}$

Clinically, the present results support the idea that the sciatic nerve contributes to the postoperative pain following TKA. Anatomically, however, our understanding of the innervation of the posterior knee is relatively incomplete as it is based primarily on anatomical descriptions dating back to more than six decades ago. ${ }^{46}$ Hence, designing trials to quantify the effect of SNB accurately when its distribution is not clearly delineated is difficult at best. Additionally, the combined innervation of the knee joint by both the femoral and sciatic nerves, and the overlap in their innervation of the anterolateral aspect of the knee, ${ }^{46}$ further complicate accurate assessment. In fact, few studies ${ }^{12}$ have conceived designs capable of reliably isolating pain transmitted by the femoral and sciatic nerves, which would permit accurate quantification 
of a block's analgesic effects on the individual nerves. ${ }^{44}$ Furthermore, the human capacity to distinguish between pain arising from two adjacent sources as separate is subject to the interplay between spatial summation ${ }^{47}$ and discrimination. ${ }^{48}$ Summation may account for a lack of difference in perceived pain arising from the anterior knee $v s$ that arising from both the anterior and posterior knee. ${ }^{49}$ Also, discrimination enables distinguishing pain from two sources only if they are $\geq 10 \mathrm{~cm}$ apart. ${ }^{50}$ Realistically, overall knee pain may be the best available surrogate measure of the analgesic effects of SNB. Finally, LIA is an emerging analgesic modality ${ }^{2}$; but whether its ultimate role in a post-TKA analgesic regimen is to complement nerve blocks $^{51}$ or replace them altogether ${ }^{52-55}$ is to be determined by future research.

Our systematic review has several areas of strength. The literature search we conducted was exhaustive and included all of the relevant electronic databases. Our eligibility criteria restricted the evidence sought to that in RCTs and excluded several observational studies ${ }^{11-13}$ that had been included in earlier reviews. ${ }^{14}$ Additionally, all of the trials we included were of high quality (Jadad score $\geq$ 3 ). These factors thus reinforce the validity of our findings.

Our systematic review, however, also has some limitations. First, the outcome data originated from varying RCT settings with diverse anesthetic and analgesic practices. For example, the nerve localization techniques employed and the analgesic regimens used varied among the trials, leading to considerable heterogeneity. We also did not use a specific type of TKA surgery to stratify our results. Variations among TKA techniques could result in differences in the duration and severity of postoperative pain as well as the dose of postoperative morphine needed to treat the pain. Second, the majority of the trials we reviewed were characterized by their small sample size, with a maximum of 33 patients per group. Such small RCTs could increase the likelihood of detecting a treatment effect and/or misestimating its magnitude because of a combination of mere chance and publication bias. Third, analgesic techniques other than SNB (e.g., intra- articular local anesthetic infiltration, ${ }^{18,23}$ posterior knee capsule injection ${ }^{56}$ have achieved effective pain relief following TKA, whether in combination with or as substitutes for SNB. The influence of the aforementioned analgesic options on SNB analgesia is not within the scope of our systematic review. Fourth, it is not possible to exclude reporting bias because publishing the study protocols on trial registration sites has not been common practice. Fifth, the reviewed RCTs used varying and sometimes unclear definitions to describe reported outcomes, which questions the validity of combining these outcome results. Sixth, this review was limited to RCTs published in English, and we did not translate any foreign trials. Seventh, although the absolute difference in pain scores may seem modest at certain time points, including at four and eight hours for SSNB, differences in pain severity scores as small as 0.9 and 1.1 units on the VAS have been proven to be clinically important. ${ }^{57,58}$ Finally, none of the RCTs described any preexisting (i.e., preoperative) knee pain, which precluded analysis of the association between this postoperative pain predictor ${ }^{59}$ and the duration of postTKA analgesia supplied by the SNB.

In conclusion, the available evidence supporting an analgesic benefit of adding SNB to FNB following TKA is marked by significant heterogeneity. Keeping this heterogeneity limitation in mind, our meta-analysis suggests that SNB can significantly reduce postoperative opioid consumption and diminish the knee pain following TKA compared to no SNB in the setting of FNB. Although analgesic strategies vary greatly across institutions, ${ }^{45,60}$ our results support a role for $\mathrm{SNB}$ in acute pain management following TKA.

Author contributions: Faraj W. Abdallah conceived the idea, helped in designing and conducting the study, collecting and analyzing the data, and preparing the final manuscript. Caveh Madjdpour helped in conducting the study, collecting and analyzing the data, and preparing the final manuscript. Richard Brull helped in designing and conducting the study, collecting and analyzing the data, and preparing the final manuscript. All authors attest to the integrity of the original data and the analysis reported in this manuscript. All authors approved of the final manuscript.

Acknowledgement We thank Marina Englesakis, Research Librarian, University Health Network, Toronto, Canada.

Sources of funding This work was supported by internal departmental funding. Drs. F. Abdallah and R. Brull were also supported by the Merit Award Program of the Department of Anesthesia, University of Toronto.

Competing interests No competing interests declared.

Appendix: Medline search strategy as: 2015-03-27

\begin{tabular}{llll}
\hline Ovid MEDLINE(R) 1950 to March Week 4 2015 & \\
\hline$\#$ & Searches & Results & $\begin{array}{l}\text { Search } \\
\text { Type }\end{array}$ \\
\hline 1 & Arthroplasty, Replacement, Knee/ & 12424 & Advanced \\
2 & Knee Prosthesis/ & 8524 & Advanced \\
3 & ((knee or knees) adj3 replac*).mp. & 15099 & Advanced \\
4 & ((knee or knees) adj3 arthroplast*).mp. & 15809 & Advanced \\
5 & ((knee or knees) adj3 prosthe*).mp. & 9624 & Advanced \\
6 & (total adj2 knee?).mp. & 12273 & Advanced \\
7 & tka.tw. [Total Knee Arthroplasty] & 3413 & Advanced \\
\hline
\end{tabular}


Appendix continued

Ovid MEDLINE(R) 1950 to March Week 42015

\begin{tabular}{|c|c|c|c|}
\hline \# & Searches & Results & $\begin{array}{l}\text { Search } \\
\text { Type }\end{array}$ \\
\hline 8 & tkr.tw. [Total Knee Replacement] & 1030 & Advanced \\
\hline 9 & tkas.tw. & 790 & Advanced \\
\hline 10 & tkrs.tw. & 175 & Advanced \\
\hline 11 & or/1-10 & 21320 & Advanced \\
\hline 12 & Knee/ & 10263 & Advanced \\
\hline 13 & exp Knee Joint/ & 42355 & Advanced \\
\hline 14 & exp Knee Injuries/ & 15682 & Advanced \\
\hline 15 & Osteoarthritis, Knee/ & 10346 & Advanced \\
\hline 16 & Patella/in [Injuries] & 1934 & Advanced \\
\hline 17 & Patella/su [Surgery] & 2229 & Advanced \\
\hline 18 & knee.tw. & 80573 & Advanced \\
\hline 19 & knees.tw. & 14927 & Advanced \\
\hline 20 & or/12-19 & 105201 & Advanced \\
\hline 21 & exp Arthroplasty/ & 39132 & Advanced \\
\hline 22 & exp Joint Prosthesis/ & 34450 & Advanced \\
\hline 23 & "Prostheses and Implants"/ & 36086 & Advanced \\
\hline 24 & arthroplast*.tw. & 32856 & Advanced \\
\hline 25 & prosthe*.tw. & 87061 & Advanced \\
\hline 26 & replac*.tw. & 282245 & Advanced \\
\hline 27 & implant*.tw. & 252903 & Advanced \\
\hline 28 & endoprosthe*.tw. & 5601 & Advanced \\
\hline 29 & exp Prosthesis Failure/ & 21219 & Advanced \\
\hline 30 & or/21-29 & 614708 & Advanced \\
\hline 31 & 20 and 30 & 27250 & Advanced \\
\hline 32 & $\begin{array}{l}11 \text { or } 31 \text { [Knee Replacement \& Related } \\
\text { Terms] }\end{array}$ & 29228 & Advanced \\
\hline 33 & exp Sciatic Nerve/ and exp Nerve Block/ & 1032 & Advanced \\
\hline 34 & $\begin{array}{l}\exp \text { Sciatic Nerve/ and exp Anesthesia, } \\
\text { Conduction/ }\end{array}$ & 1139 & Advanced \\
\hline 35 & (sciatic nerve* adj3 block*).mp. & 728 & Advanced \\
\hline 36 & (sciatic adj3 block*).mp. & 830 & Advanced \\
\hline 37 & snb.tw. [Sciatic Nerve Block] & 1127 & Advanced \\
\hline 38 & or/33-37 & 2491 & Advanced \\
\hline 39 & 32 and 38 & 97 & Advanced \\
\hline 40 & limit 39 to english language & 81 & Advanced \\
\hline
\end{tabular}

\section{References}

1. Weinstein AM, Rome BN, Reichmann WM, et al. Estimating the burden of total knee replacement in the United States. J Bone Joint Surg Am 2013; 95: 385-92.

2. Rasmussen S, Kramhoft $M U$, Sperling KP, Pedersen $J H$. Increased flexion and reduced hospital stay with continuous intraarticular morphine and ropivacaine after primary total knee replacement: open intervention study of efficacy and safety in 154 patients. Acta Orthop Scand 2004; 75: 606-9.
3. Jenstrup MT, Jaeger P, Lund J, et al. Effects of adductor-canalblockade on pain and ambulation after total knee arthroplasty: a randomized study. Acta Anaesthesiol Scand 2012; 56: 357-64.

4. Mariano ER, Perlas A. Adductor canal block for total knee arthroplasty: the perfect recipe or just one ingredient? Anesthesiology 2014; 120: 530-2.

5. Sato $K$, Adachi $T$, Shirai $N$, Naoi $N$. Continuous versus singleinjection sciatic nerve block added to continuous femoral nerve block for analgesia after total knee arthroplasty: a prospective, randomized, double-blind study. Reg Anesth Pain Med 2014; 39: 225-9.

6. Yamamoto H, Sakura S, Wada M, Shido A. A prospective, randomized comparison between single- and multiple-injection techniques for ultrasound-guided subgluteal sciatic nerve block. Anesth Analg 2014; 119: 1442-8.

7. Patel N, Solovyova O, Matthews G, Arumugam S, Sinha SK, Lewis $C G$. Safety and efficacy of continuous femoral nerve catheter with single shot sciatic nerve block vs epidural catheter anesthesia for same-day bilateral total knee arthroplasty. J Arthroplasty 2015; 30: 330-4.

8. Carvalho Junior LH. Temponi EF, Paganini VO, Costa LP, Soares $L F$, Gonçalves $M B$. Reducing the length of hospital stay after total knee arthroplasty: influence of femoral and sciatic nerve block. Rev Assoc Med Bras 2015; 61: 40-3.

9. Al-Zahrani $T$, Doais KS, Aljassir F, Alshaygy I, Albishi W, Terkawi AS. Randomized clinical trial of continuous femoral nerve block combined with sciatic nerve block versus epidural analgesia for unilateral total knee arthroplasty. J Arthroplasty 2015; 30: 149-54

10. Bonica JJ. Postoperative pain. In: Bonica JJ, editor. The Management of Pain. 2nd ed. Philadelphia, PA: Lea \& Febiger, Malvern; 1990

11. Cook P, Stevens J, Gaudron C. Comparing the effects of femoral nerve block versus femoral and sciatic nerve block on pain and opiate consumption after total knee arthroplasty. J Arthroplasty 2003; 18: 583-6.

12. Ben-David B, Schmalenberger $K$, Chelly JE. Analgesia after total knee arthroplasty: is continuous sciatic blockade needed in addition to continuous femoral blockade? Anesth Analg 2004; 98: 747-9.

13. Weber A, Fournier R, Van Gessel E, Gamulin Z. Sciatic nerve block and the improvement of femoral nerve block analgesia after total knee replacement. Eur J Anaesthesiol 2002; 19: 834-6.

14. Abdallah $F W$, Brull $R$. Is sciatic nerve block advantageous when combined with femoral nerve block for postoperative analgesia following total knee arthroplasty? A systematic review. Reg Anesth Pain Med 2011; 36: 493-8.

15. Cappelleri $G$, Ghisi D, Fanelli A, Albertin A, Somalvico $F$, Aldegheri $G$. Does continuous sciatic nerve block improve postoperative analgesia and early rehabilitation after total knee arthroplasty? A prospective, randomized, double-blinded study. Reg Anesth Pain Med 2011; 36: 489-92.

16. Wegener JT, van Ooij B, van Dijk CN, Hollmann MW, Preckel B, Stevens $M F$. Value of single-injection or continuous sciatic nerve block in addition to a continuous femoral nerve block in patients undergoing total knee arthroplasty: a prospective, randomized, controlled trial. Reg Anesth Pain Med 2011; 36: 481-8.

17. Serrano A, Santiveri X, Bisbe E, Ortiz P, Puig L, Castillo J. Analgesic efficacy of associating a sciatic block to a femoral block in the posotperative period of total knee arthroplasty: 8AP4-9. Eur J Anaesthesiol 2011; 28: 119-20.

18. Mahadevan D, Walter RP, Minto G, Gale TC, McAllen CJ, Oldman $M$. Combined femoral and sciatic nerve block vs combined femoral and periarticular infiltration in total knee arthroplasty: a randomized controlled trial. J Arthroplasty 2012; 27: 1806-11. 
19. Carvalho $R$, Calixto L, Braganca JP. Effect of a single shot sciatic nerve block combined with a continuous femoral block on pain scores after knee arthroplasty. A randomized controlled trial. Open J Anesthesiol 2012; 2: 107-12.

20. Sinha SK, Abrams JH, Arumugam S, et al. Femoral nerve block with selective tibial nerve block provides effective analgesia without foot drop after total knee arthroplasty: a prospective, randomized, observer-blinded study. Anesth Analg 2012; 115: 202-6.

21. Safa B, Gollish J, Haslam L, McCartney CJ. Comparing the effects of single shot sciatic nerve block versus posterior capsule local anesthetic infiltration on analgesia and functional outcome after total knee arthroplasty: a prospective, randomized, doubleblinded, controlled trial. J Arthroplasty 2014; 29: 1149-53.

22. Yoshinuma H, Hara K, Sugimura K, Makino S, Nakamura K, Osamи K. Sciatic nerve block provide superior analgesia for popliteal pain after total knee arthroplasty: 8AP7-1. Eur J Anaesthesiol 2013; 30: 134.

23. Gi E, Yamauchi $M$, Yamakage $M$, et al. Effects of local infiltration analgesia for posterior knee pain after total knee arthroplasty: comparison with sciatic nerve block. J Anesth 2014; 28: 696-701.

24. Moher D, Liberati A, Tetzlaff J. Altman DG; PRISMA Group. Preferred reporting items for systematic reviews and metaanalyses: the PRISMA statement. Int J Surg 2010; 8: 336-41.

25. Campbell WC. Arthroplasty of the knee-report of cases. J Orthop Surg 1921; 3: 430-4.

26. Moore DC. Sciatic and femoral nerve block. J Am Med Assoc 1952; 150: 550-4.

27. Jadad AR, Moore RA, Carroll D, et al. Assessing the quality of reports of randomized clinical trials: is blinding necessary? Control Clin Trials 1996; 17: 1-12.

28. Abdallah FW, Chan VW, Gandhi R, Koshkin A, Abbas S, Brull R. Analgesic effects of proximal, distal, or no sciatic nerve block on posterior knee pain after total knee arthroplasty: a double-blind placebo-controlled randomized trial. Anesthesiology 2014; 121: 1302-10.

29. Ballantyne JC, Carr DB, Chalmers TC, Dear KB, Angelillo IF, Mosteller F. Postoperative patient-controlled analgesia: metaanalyses of initial randomized control trials. J Clin Anesth 1993; 5: $182-93$

30. Ploghaus A, Narain C, Beckmann CF, et al. Exacerbation of pain by anxiety is associated with activity in a hippocampal network. $\mathrm{J}$ Neurosci 2001; 21: 9896-903.

31. Khan RS, Ahmed K, Blakeway E, et al. Catastrophizing: a predictive factor for postoperative pain. Am J Surg 2011; 201: 122-31.

32. Breivik EK, Bjornsson GA, Skovlund E. A comparison of pain rating scales by sampling from clinical trial data. Clin J Pain 2000; 16: 22-8.

33. Canadian Pharmacists Association. CPS 2010 - Compendium of Pharmaceuticals and Specialties - The Canadian Drug Reference for Health Professionals -. 45th ed. Ottawa, ON, Canada: Canadian Pharmacists Assoc; 2010.

34. Hozo S, Djulbegovic B, Hozo I. Estimating the mean and variance from the median, range, and the size of a sample. BMC Med Res Methodol 2005; 5: 13-23.

35. Higgins JP, Altman DG, Gotzsche PC, et al. The Cochrane Collaboration's tool for assessing risk of bias in randomised trials. BMJ 2011; 343: d5928.

36. Higgins JP, Thompson SG. Quantifying heterogeneity in a metaanalysis. Stat Med 2002; 21: 1539-58.

37. Song F, Sheldon TA, Sutton AJ, Abrams KR, Jones DR. Methods for exploring heterogeneity in meta-analysis. Eval Health Prof 2001; 24: 126-51.
38. Allen HW, Liu SS, Ware PD, Nairn CS, Owens BD. Peripheral nerve blocks improve analgesia after total knee replacement surgery. Anesth Analg 1998; 87: 93-7.

39. Hunt K, Bourne M, Mariani EM. Single-injection femoral and sciatic nerve blocks for pain control after total knee arthroplasty. J Arthroplasty 2009; 24: 533-8.

40. Pham Dang C, Gautheron E, Guilley J, et al. The value of adding sciatic block to continuous femoral block for analgesia after total knee replacement. Reg Anesth Pain Med 2005; 30: 128-33.

41. Morin AM, Kratz CD, Eberhart LH, et al. Postoperative analgesia and functional recovery after total-knee replacement: comparison of a continuous posterior lumbar plexus (psoas compartment) block, a continuous femoral nerve block, and the combination of a continuous femoral and sciatic nerve block. Reg Anesth Pain Med 2005; 30: 434-45.

42. OCEBM Levels of Evidence Working Group:."the Oxford 2011 Levels of Evidence". : Oxford Centre for Evidence-Based Medicine. Available from URL: http://www.cebm.net/ocebmlevels-of-evidence/ (accessed November 2015).

43. Maheshwari AV, Blum YC, Shekhar L, Ranawat AS, Ranawat CS. Multimodal pain management after total hip and knee arthroplasty at the Ranawat Orthopaedic Center. Clin Orthop Relat Res 2009; 467: 1418-23.

44. Abdallah $F W$, Brull R. Sciatic nerve block for analgesia after total knee arthroplasty: the jury is still out. Reg Anesth Pain Med 2012; 37: 122-3.

45. Ilfeld BM, Madison SJ. The sciatic nerve and knee arthroplasty: to block, or not to block-that is the question. Reg Anesth Pain Med 2011; 36: 421-3.

46. Gardner E. The innervation of the knee joint. Anat Rec 1948; 101: 109-30.

47. Hardy JD, Wolff $H G$, Goodell $H$. Studies on pain. A new method for measuring pain threshold: observations on spatial summation of pain. J Clin Invest 1940; 19: 649-57.

48. Price DD, McHaffie JG, Larson MA. Spatial summation of heatinduced pain: Influence of stimulus area and spatial separation of stimuli on perceived pain sensation intensity and unpleasantness. J Neurophysiol 1989; 62: 1270-9.

49. Marchand $S$, Arsenault $P$. Spatial summation for pain perception: interaction of inhibitory and excitatory mechanisms. Pain 2002; 95: 201-6.

50. Defrin R, Givon R, Raz N, Urca G. Spatial summation and spatial discrimination of pain sensation. Pain 2006; 126: 123-31.

51. Parvataneni HK, Shah VP, Howard H, Cole $N$, Ranawat AS, Ranawat CS. Controlling pain after total hip and knee arthroplasty using a multimodal protocol with local periarticular injections: a prospective randomized study. J Arthroplasty 2007; 22(6 Suppl 2): 33-8.

52. Toftdahl K, Nikolajsen L, Haraldsted V, Madsen F, Tonnesen EK, Soballe $K$. Comparison of peri-and intraarticular analgesia with femoral nerve block after total knee arthroplasty: a randomized clinical trial. Acta Orthop 2007; 78: 172-9.

53. Carli $F$, Clemente A, Asenjo JF, et al. Analgesia and functional outcome after total knee arthroplasty: periarticular infiltration vs continuous femoral nerve block. Br J Anaesth 2010; 105: 185-95.

54. Affas $F$, Nygards EB, Stiller CO, Wretenberg P, Olofsson C. Pain control after total knee arthroplasty: a randomized trial comparing local infiltration anesthesia and continuous femoral block. Acta Orthop 2011; 82: 441-7.

55. Arthur CM, Wood AM, Leeson-Payne C, Breusch SJ. Comparason of peri-articular multimodal drug injection with femoral and sciatic nerve block after total knee arthroplasty. Open J Orthop 2012; 2: 155-8.

56. Rooney EM, Lang SA, Klassen L, Dust WN, Yip RW, Morris GF. Intraoperative transcruciate injection: a new approach to 
postoperative analgesia following total knee arthroplasty. Reg Anesth Pain Med 1998; 23: 34.

57. Todd KH, Funk KG, Funk JP, Bonacci $R$. Clinical significance of reported changes in pain severity. Ann Emerg Med 1996; 27: 485-9.

58. Kelly AM. The minimum clinically significant difference in visual analogue scale pain score does not differ with severity of pain. Emerg Med J 2001; 18: 205-7.
59. Valencia $C$, Fillingim RB, Bishop $M$, et al. Investigation of central pain processing in postoperative shoulder pain and disability. Clin J Pain 2014; 30: 775-86.

60. Hennessy B. The easy option? Anaesth Intensive Care 2013; 41: 456-7. 